\title{
Magnetic Transformation and the Influence of Plastic Strain on the Shear Modulus of Fe-Cr-Ni alloys
}

\author{
R. P. Mikesell* and R. P. Reed* \\ Institute for Materials Research, National Bureau of Standards, Boulder, Colo.
}

(March 31, 1966)

\begin{abstract}
The Fe-18Cr-9Ni and Fe-19Cr-9Ni alloys exhibıt a decrease in shear modulus between 76 and $20{ }^{\circ} \mathrm{K}$. Susceptibility measurements confirm that a paramagnetic to antiferromagnetic transition occurs at about $40{ }^{\circ} \mathrm{K}$ in these alloys. The shear modulus for the $\mathrm{Fe}-25 \mathrm{Cr}-21 \mathrm{Ni}$ alloy did not decrease between 76 and $20^{\circ} \mathrm{K}$ which was consistent with the fact that the alloy remained paramagnetic to $4{ }^{\circ} \mathrm{K}$. The effect of cold-work on the shear modulus above and below the Néel temperature is discussed.

Key Words: Antiferromagnetic, cold-work, Fe-Ni-Cr alloys, Néel temperature, shear modulus, stainless steel.
\end{abstract}

\section{Introduction}

It has been shown that the shear and Young's modulus of a $\mathrm{Fe}-19 \mathrm{Cr}-9 \mathrm{Ni}$ (weight percent) steel exhibits a decrease between 76 and $20{ }^{\circ} \mathrm{K}[1] .{ }^{1} \mathrm{Re}$ cently, investigators $[2,3,4]$ have reported a paramagnetic to antiferromagnetic transition in certain $18 \mathrm{Cr}-9 \mathrm{Ni}$ steels at about $40^{\circ} \mathrm{K}$. Since it is expected that such a magnetic transition would affect the elastic moduli, a study was made to better understand the effect of the transition on the shear modulus of $\mathrm{Fe}$ $\mathrm{Ni}-\mathrm{Cr}$ alloys. These alloys were $\mathrm{Fe}-18 \mathrm{Cr}-9 \mathrm{Ni}, \mathrm{Fe}-$ $19 \mathrm{Cr}-9 \mathrm{Ni}$, and Fe-25Cr-21Ni and correspond, respectively, to A.I.S.I. commercial stainless steel grades 303,302 , and 310 . In addition, the effect of prior plastic strain at ambient temperatures on the change of shear modulus in the temperature range 295 to $20^{\circ} \mathrm{K}$ was documented.

Some data have been reported concerning the combined effects of a magnetic transition and plastic strain on the decrease of elastic moduli on cooling below the transition temperature. Various workers have noted a change in the Young's and shear modulus of materials that have been cooled at zero magnetic field through the ferromagnetic Curie temperature [5-10]. Others have noticed the effect of a paramagnetic to antiferromagnetic transition on the elastic properties of $\mathrm{Cr}[11,14,15]$ and $\mathrm{Cu}-\mathrm{Mn}$ alloys [12]. Recently, Roberson and Lipsitt have reported that the Young's modulus and the shear modulus behave differently when $\mathrm{Cr}$ is cooled through and below the Néel temperature [16]. They found that the $\Delta E$ (the change in modulus on cooling through the transition temperature) for the shear modulus was less than

\footnotetext{
*Cryogenics Division, National Bureau of Standards, Boulder, Colo.

'Figures in brackets indicate the literature references at the end of this paper.
}

for the Young's modulus. Several investigators have noted that the $\Delta E$ effect is less for cold-worked materials than annealed materials in $\mathrm{Fe}-\mathrm{Ni}-\mathrm{Mo}$ [6], $\mathrm{Cr}$ [16, 18, 19], and $\mathrm{Ni}$ [17].

Many have noted a change in elastic modulus after plastic strain at ambient temperatures. Although some anomalies exist, results on copper. $[22,23,24$, 27-30] aluminum, [20, 21, 25, 26] and silver [27] indicate that the elastic moduli are lowered by as much as 15 percent when the material is previously plastically strained.

Susceptibility measurements described in this paper show that the Fe-18Cr-9Ni and Fe-19Cr-9Ni alloys become antiferromagnetic at 43 and $39{ }^{\circ} \mathrm{K}$, respectively, and that the $\mathrm{Fe}-25 \mathrm{Cr}-21 \mathrm{Ni}$ alloy remains paramagnetic down to $4{ }^{\circ} \mathrm{K}$. The magnitude of decrease in modulus between 76 and $20^{\circ} \mathrm{K}$ for the $18 \mathrm{Cr}-9 \mathrm{Ni}$ and $19 \mathrm{Cr}-9 \mathrm{Ni}$ alloys was found to be inversely related to the amount of prior cold-work.

\section{Procedure and Results of Susceptibility Measurements}

The susceptibility samples were made from the same bar stock that was used for the modulus specimens. The composition, hardness, condition and grain size of the alloys are listed in table I. The susceptibility was measured by the ballistic method. Values of susceptibility are plotted in arbitrary units; the units of flux change can be converted to susceptibility values through calibration of the apparatus A continuous temperature change of the sample was achieved by allowing the sample to warm from a liquid helium bath. The temperature gradient was less than $1^{\circ} \mathrm{K}$ in the sample upon warming. Values of susceptibility were reproducible with \pm 1 percent; the temperature was reproducible within $\pm 1{ }^{\circ} \mathrm{K}$. 


\begin{tabular}{|c|c|c|c|c|c|c|c|c|c|c|c|c|}
\hline \multirow[b]{2}{*}{ Alloy } & \multicolumn{9}{|c|}{ Chemical Composition (weight \%) } & \multirow{2}{*}{$\begin{array}{l}\text { Rockwell } \\
\text { Hardness } \\
\text { (B scale) }\end{array}$} & \multirow[b]{2}{*}{ Condition } & \multirow{2}{*}{$\begin{array}{l}\text { ASTM } \\
\text { Grain } \\
\text { Size }\end{array}$} \\
\hline & $\mathrm{C}$ & $\mathrm{P}$ & $\mathrm{S}$ & $\mathrm{Ni}$ & $\mathrm{Cr}$ & Mo & $\mathrm{Mn}$ & $\mathrm{Si}$ & $\mathrm{Cu}$ & & & \\
\hline \multirow{2}{*}{$\begin{array}{l}19 \mathrm{Cr}-9 \mathrm{Ni} \\
\text { (Commercial } \\
\text { AISI 302) }\end{array}$} & 0.08 & 0.02 & 0.01 & 8.7 & 18.6 & & 0.6 & 0.6 & & $R_{B} 90$ & $\begin{array}{l}\text { Annealed } \\
(\sim 0.5 \% \text { martensite })\end{array}$ & 5 \\
\hline & & & & & & & & & & $\mathrm{R}_{\mathrm{B}} 104$ & $\begin{array}{l}\text { Drawn } 14 \% \text { at } \\
\text { room temperature } \\
(\sim 13 \% \text { martensite })\end{array}$ & 5 \\
\hline \multirow{3}{*}{$\begin{array}{l}18 \mathrm{Cr}-9 \mathrm{Ni} \\
\text { (Commercial } \\
\text { AISI 303) }\end{array}$} & 0.10 & 0.03 & 0.29 & 8.7 & 17.6 & 0.4 & 1.2 & 0.6 & 0.4 & $R_{B} 81$ & Annealed & 6 \\
\hline & & & & & & & & & & $R_{B} 87$ & $\begin{array}{l}\text { Drawn } 5 \% \text { at } \\
\text { room temperature }\end{array}$ & 6 \\
\hline & & & . & & & & & & & $R_{B} 95$ & $\begin{array}{l}\text { Drawn } 13 \% \text { at } \\
\text { room temperature }\end{array}$ & 7 \\
\hline \multirow{2}{*}{$\begin{array}{l}25 \mathrm{Cr}-21 \mathrm{Ni} \\
\text { (Commercial } \\
\text { AISI } 310 \text { ) }\end{array}$} & 0.08 & 0.02 & 0.02 & 20.8 & 24.8 & 0.1 & 1.7 & 0.7 & 0.1 & $\mathrm{R}_{\mathrm{B}} 79$ & Annealed & 2 \\
\hline & & & & & & & & & & $R_{B} 89$ & $\begin{array}{l}\text { Drawn } 11 \% \text { at } \\
\text { room temperature }\end{array}$ & 2 \\
\hline
\end{tabular}

Results of the susceptibility measurements for 19Cr$9 \mathrm{Ni}, 18 \mathrm{Cr}-9 \mathrm{Ni}$ and $25 \mathrm{Cr}-21 \mathrm{Ni}$ alloys are shown in figure 1 . The annealed $19 \mathrm{Cr}-9 \mathrm{Ni}$ and annealed $18 \mathrm{Cr}$ $9 \mathrm{Ni}$ were measured with a field of about $1 \mathrm{kG}$; annealed and 11 percent cold-drawn $25 \mathrm{Cr}-21 \mathrm{Ni}$ were measured with a field of about $0.4 \mathrm{kG}$. The $19 \mathrm{Cr}-9 \mathrm{Ni}$ specimen, when plastically strained 14 percent, exhibited a partial phase transformation to body-centered cubic martensite. The body-centered cubic phase is ferromagnetic [31]. Therefore, the susceptibility measurements to determine the antiferromagnetic transition were thwarted by the stronger ferromagnetism from the martensite phase. Although the 18Cr-9Ni alloy has similar $\mathrm{Cr}$ and $\mathrm{Ni}$ content, the amount of other stabilizing elements (see table I) is greater, which explains the lack of detectable amounts of martensite formed by plastic deformation. Since the susceptibility versus temperature measurements for the $18 \mathrm{Cr}-9 \mathrm{Ni}$ cold-drawn specimens were appreciably smeared out, it was difficult to detect a distinct inflection temperature.

\section{Procedure and Results of Shear Modulus Measurements}

The method of determining the shear modulus has been previously described [32]. Briefly, the method consisted of applying small incremental torque loads to carefully machined specimens and measuring the

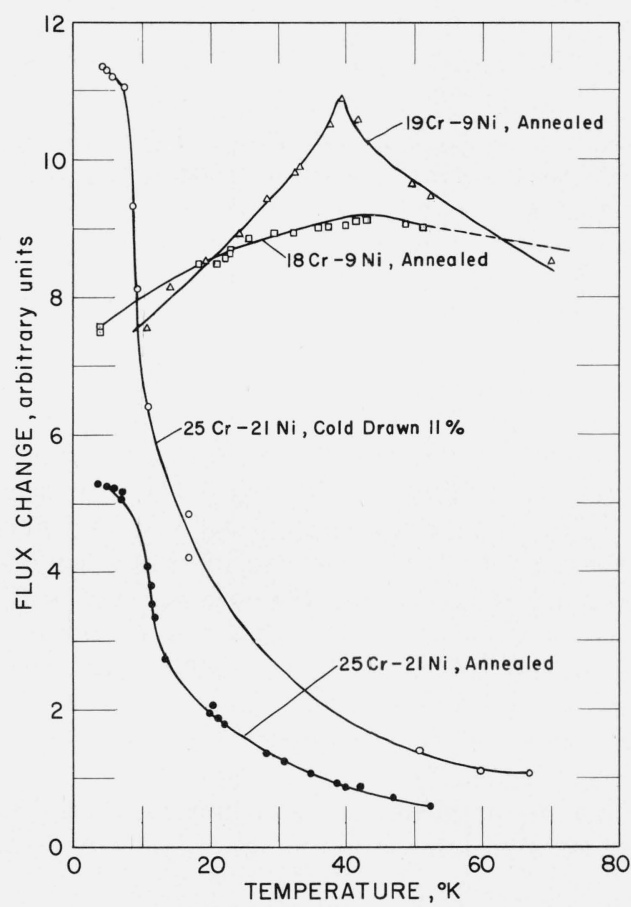

FIGURE 1. The flux change, proportional to the magnetic susceptibility, as a function of temperature for $19 \mathrm{Cr}-9 \mathrm{Ni}$ steel, $18 \mathrm{Cr}-9 \mathrm{Ni}$ steel, and $25 \mathrm{Cr}-21 \mathrm{Ni}$ steel. 
angle of displacement using an optical lever. The maximum shear stress applied to all the samples was 2900 psi. Measurements were made at three temperatures: 295,76 , and $20^{\circ} \mathrm{K}$. Results are shown in figures 2,3 , and 4 .

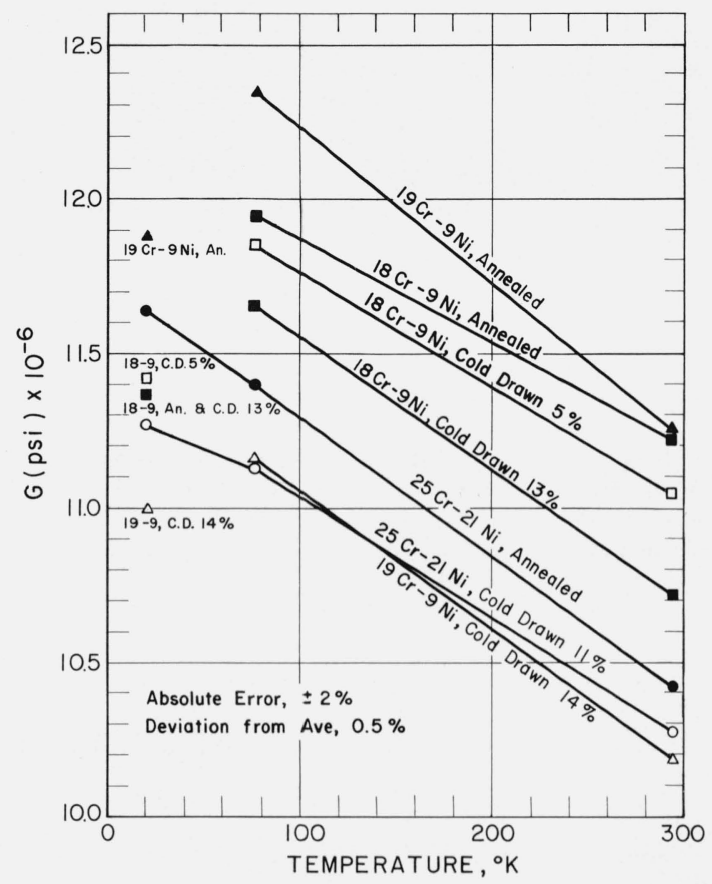

Figure 2. The shear moduli of $19 \mathrm{Cr}-9 \mathrm{Ni}, 18 \mathrm{Cr}-9 \mathrm{Ni}$, and $25 \mathrm{Cr}-21 \mathrm{Ni}$ steels as a function of temperature.

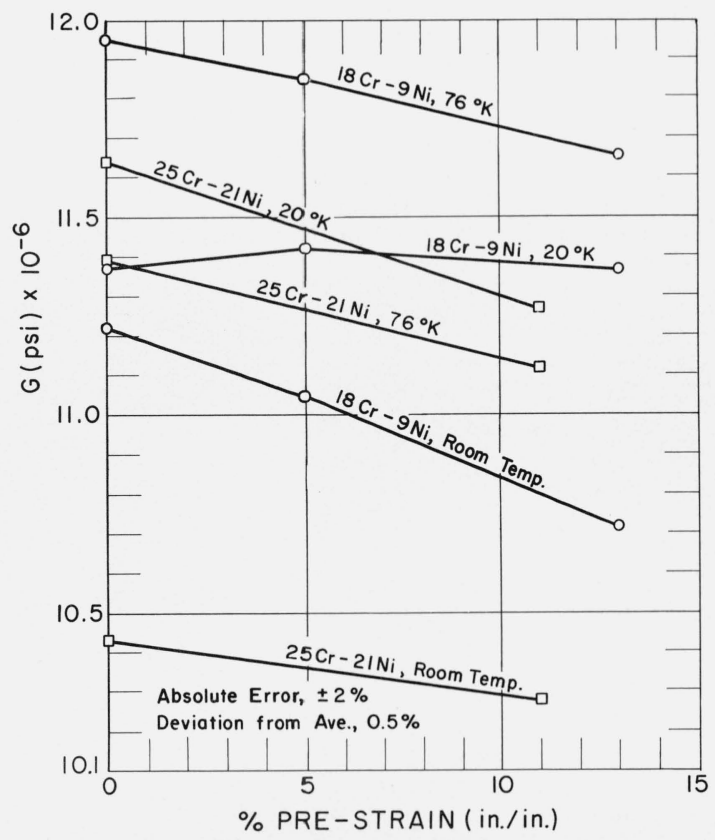

Figure 3. The shear moduli of $18 \mathrm{Cr}-9 \mathrm{Ni}$ and $25 \mathrm{Cr}-21 \mathrm{Ni}$ steels at constant temperature as a function of prior plastic strain.

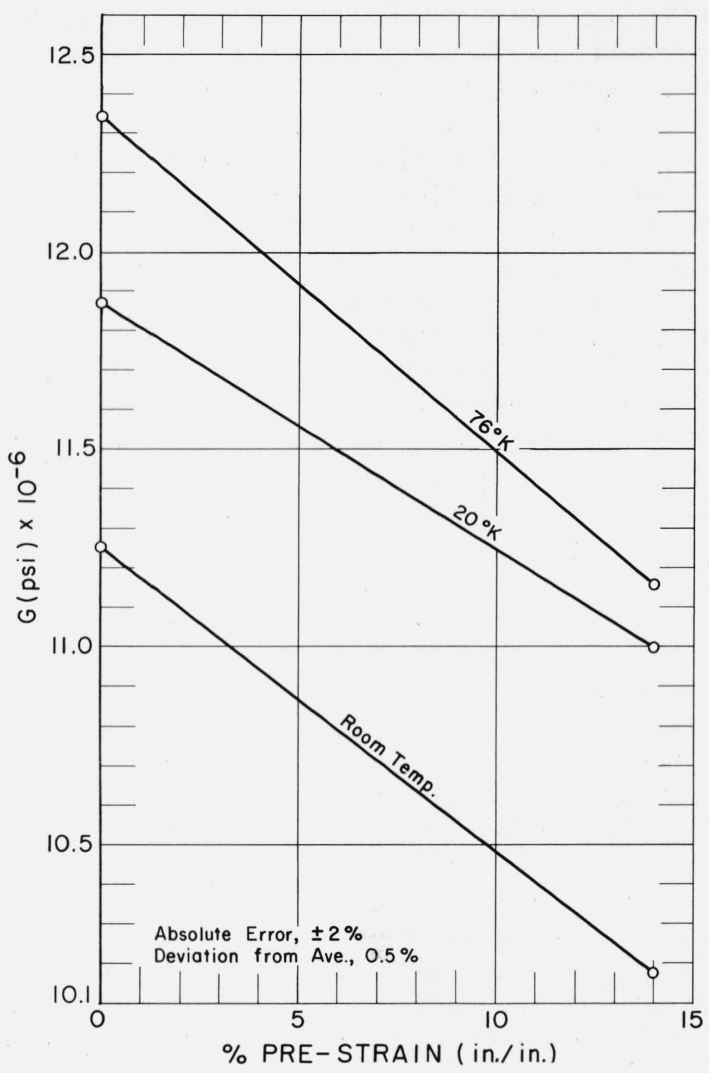

FIGURE 4. The shear modulus of $19 \mathrm{Cr}-9 \mathrm{Ni}$ steel at constant temperature as a function of prior plastic strain.

For any one sample and at any one temperature, the deviation from the average value of modulus is 0.5 percent. The maximum absolute error, i.e., the error that occurs either on repeating measurements after removal and remounting of the sample, or on measuring another specimen of the same alloy, is \pm 2 percent.

\section{Discussion}

In figure 1 it is seen that the $19 \mathrm{Cr}-9 \mathrm{Ni}$ and $18 \mathrm{Cr}-9 \mathrm{Ni}$ alloys each show a peak in the susceptibility-temperature curve which is characteristic of a material transforming from a paramagnetic to an antiferromagnetic state. These results are consistent with the modulus curves of figure 2 ; the $19 \mathrm{Cr}-9 \mathrm{Ni}$ and $18 \mathrm{Cr}-9 \mathrm{Ni}$ alloys exhibit anomalous drops in modulus whereas the $25 \mathrm{Cr}$ $21 \mathrm{Ni}$ alloy behaves normally down to $20^{\circ} \mathrm{K}$. The decrease in modulus between 76 and $20^{\circ} \mathrm{K}$ is due to an additional strain component resulting from antiferromagnetic ordering below the Néel temperature [12, 13].

From the $18 \mathrm{Cr}-9 \mathrm{Ni}$ and $19 \mathrm{Cr}-9 \mathrm{Ni}$ alloy shear modulus curves of figure 2 , it is seen that $\left(G_{76^{\circ}}-G_{20^{\circ}}\right) / G_{76^{\circ}}$ is inversely related to the amount of prior plastic strain: the $\Delta G / G$ for the $18 \mathrm{Cr}-9 \mathrm{Ni}$ alloy is respectively 4.9 , 3.6 , and 2.6 percent for annealed, 5 percent cold-drawn, and 13 percent cold-drawn conditions; $\Delta G / G$ for the 
19Cr-9Ni alloy decreased from 3.6 to 1.4 percent for the annealed to cold-drawn conditions. This decrease indicates that there is less magnetostrictive effect at $20{ }^{\circ} \mathrm{K}$ in a cold-worked sample due to internal stresses from defects which influence the redistribution of the domain vectors $[35,6]$.

The effect of prior plastic strain above the Néel temperature on the shear modulus is illustrated in figures 2 to 4 . A decrease of the modulus values, after straining, has been verified. This is expected since many of the dislocations introduced during plastic straining move under very low stresses. In addition, vacancies created by cold-work lower the material density which lowers the modulus. Jongenburger [33] has predicted that materials with low stacking fault energy would exhibit greater sensitivity to coldwork than high stacking fault energy materials, since the stress needed to move extended dislocations should be less. The $18 \mathrm{Cr}-9 \mathrm{Ni}$ alloy is expected to have a lower stacking fault energy than the $25 \mathrm{Cr}-21 \mathrm{Ni}$ alloy [34]. At ambient temperatures the strain sensitivity of the shear modulus for the $18 \mathrm{Cr}-9 \mathrm{Ni}$ alloy is greater; however, at $76^{\circ} \mathrm{K}$ their sensitivities are approximately equal. The reason for this temperature trend is not clear.

At $20^{\circ} \mathrm{K}$, notice that the shear modulus of the $18 \mathrm{Cr}$ $9 \mathrm{Ni}$ alloy is essentially independent of the amount of prior plastic strain. Apparently the $\Delta E$ effect and the defect contribution, which serves to lower the overall modulus, just offset each other at this temperature. The much greater reduction of the shear modulus of the $19 \mathrm{Cr}-9 \mathrm{Ni}$ alloy as a function of strain is undoubtedly influenced by the partial transformation to the martensite (body centered cubic) phase during plastic deformation at room temperature.

\section{Summary}

It has been found that the elastic properties of low stacking fault energy austenitic stainless steels undergo a transition at about $40^{\circ} \mathrm{K}$. This transition produces a decrease in the shear modulus values and is caused by a paramagnetic to antiferromagnetic transformation. The decrease of the modulus values between 76 and $20^{\circ} \mathrm{K}$ is inversely related to the amount of prior cold-work at ambient temperature. The shear modulus at temperatures above the Néel temperature is influenced by previous cold-work, decreasing up to 10 percent for 10 to 15 percent plastic strain.

\section{References}

[1] R. P. Reed and R. P. Mikesell, Adv. in Cryogenic Engr. 10, 46 (Plenum Press, New York, 1964).

[2] E. I. Kondorskii and V. L. Sedov, J. Exptl. Theoret. Phys. (USSR) 35, 1579 (1958); Soviet Physics JEPT 35 (8), 1104 (1959).

[3] W. H. Meikeljohn, J. Appl. Phys. 32S, 274S (1961).

[4] U. Gonser, C. J. Meedhan, A. H. Muir, and H. Wiedersich, J. Appl. Phys. 34, 2373 (1963).

[5] O. Engler, Ann. Physik. 31, 145 (1938).

[6] M. E. Fine and W. C. Ellis, Trans. A.I.M.E. 188, 1120 (1950).

[7] M. E. Fine and W. C. Ellis, Trans. A.I.M.E. 191, 761 (1951).

[8] K. P. Belov, G. I. Kataev, and R. Z. Levitin, J. Exptl. Theroet. Phys. (USSR) 37,670 (1959).

[9] G. I. Kataev and Z. D. Sirota, J. Exptl. Theoret. Phys. (USSR) 38, 747 (1960).

[10] G. I. Kataev, Fiz. Metal. Metalloved. 11, No. 3, 375 (1961); Phys. of Metals and Metallography 11, No. 3, 53 (1961).

[11] M. E. Fine, E. S. Greiner, and W. C. Ellis, Trans. A.I.M.E. 191 56 (1951).

[12] R. Street and J. H. Smith, J. Physique et le Radium 20, 82 (1959).

[13] R. Street, J. Appl. Phys. 31S, 310 S (1960).

[14] D. I. Bolef and J. de Klerk, Phys. Rev. 129, 1063 (1963).

[15] M. E. de Morton, Phys. Rev. Letters 10, 208 (1963).

[16] J. A. Roberson and H. A. Lipsitt, J. Appl. Phys. 36, 2843 (1965).

[17] W. Köster, Z. Metallkunde 35, 57 (1943).

[18] R. Street, Phys. Rev. Letters 10, 210 (1963).

[19] M. J. Klein, A. H. Clauer, and R. E. Maringer, J. Appl. Phys. 35, 1994 (1964).

[20] M. Kornfeld, Phys. Z. Sov. 6, 329 (1934).

[21] W. Koster, Z. Metallkunde 32, 382 (1940).

[22] A. D. N. Smith, Phil Mag. 44, 453 (1953).

[23] M. Cook, T. Richards, and G. F. Bidmead, J. Inst. Met. 83, 41 (1954-55).

[24] E. C. Crittenden, Jr., and H. Dieckamp, Phys Rev. 91, 232(A) (1953); 94, 1421(A) (1954).

[25] J. Friedel, C. Boulander, and C. Crussard, Acta Met. 3, 380 (1955).

[26] M. J. Hordon, B. S. Lement, and B. L. Averbach, Acta Met. 6, 446 (1958).

[27] M. J. Druyvesteyn, O. F. Z. Schannen, and E. C. J. Swaving, Physica. 25, 1271 (1959).

[28] G. A. Alers and D. O. Thompson, J. Appl. Phys. 32, 283 (1961).

[29] W. Lems, Physica. 28, 445 (1962).

[30] W. F. Druyvesteyn and B. S. Blaisse, Physica. 28, 695 (1962).

[31] R. P. Reed and R. P. Mikesell, Adv. in cryogenic Engr. 4, 84 (Plenum Press, New York, 1958).

[32] R. P. Mikesell and R. M. McClintock, Adv. in Cryogenic Engr. 7, 509 (Plenum Press, New York, 1961).

[33] P. Jongenburger, Acta Met. 1 1, 992 (1963).

[34] J. F. Breedis, Acta Met. 13, 239 (1965).

[35] R. M. Bozorth, Ferromagnetism (Van Nostrand, New York, 1951).

The authors thank J. J. Gniewek for informal discussions regarding the work in this paper.

(Paper 70C3-232) 